\title{
Identifying Predictors of the Visceral Fat Index in the Obese and Overweight Population to Manage Obesity: A Randomized Intervention Study
}

\author{
Lourdes López-Hernández $^{a} \quad$ Pilar Pérez-Ros $^{a} \quad$ María Fargueta $^{b}$ \\ Laura Elvirab $^{b}$ Josep López-Soler ${ }^{b}$ Ana Pablos ${ }^{b}$ \\ aDepartment of Nursing, Universidad Católica de Valencia San Vicente Mártir, Valencia, \\ Spain; ${ }^{\mathrm{b}}$ Faculty of Physical Activity and Sport Sciences, Universidad Católica de Valencia \\ San Vicente Martir, Valencia, Spain
}

\author{
Keywords \\ Obesity $\cdot$ Visceral fat $\cdot$ Exercise $\cdot$ Social class $\cdot$ Eating habits
}

\begin{abstract}
Introduction: Nowadays, obesity is one of the main causes of death and disability. In recent years, it has been shown that the excess and distribution of body fat increases morbidity, with excess visceral fat being the most important factor that triggers pathologies. Thus, estimation of visceral fat makes it possible to identify patients with a higher cardiovascular risk, aiding the management of obesity. The main objective of the study was to identify predictors of the visceral fat index through a lifestyle intervention and to observe the effect of the intervention on dietary habits and functional capacity. Methods: A randomized intervention, parallel-group study was made. This study included 97 obese and overweight people (control group, $n=48$; experimental group, $n=49$ ) with a low socioeconomic status in an 8-month lifestyle intervention. Anthropometric, fitness and nutritional tests were assessed. Results: It was found that being female, eating the recommended daily portions of fruit, gaining strength in the legs and gaining flexibility are factors predictive of a lower visceral fat index. Age over 45 years and eating the recommended weekly portions of cereals and meats, fat and processed meats increases the visceral fat index after a lifestyle intervention. There were changes in the visceral fat index and in the different physical condition variables, but not in eating habits. Conclusion: $\mathrm{A}$ multicomponent lifestyle intervention reduces the visceral fat index; age over 45 and consuming cereals and meat increases the visceral fat index.


López-Hernández et al.: Predictors of Visceral Fat in the Obese Population

\section{Introduction}

In recent decades, obesity has tripled worldwide [1], constituting one of the main causes of death and disability and being associated, among other comorbidities, with an increased risk of cardiovascular disease [2-4].

In the case of Spain, the estimated prevalence of overweight in the adult population (age $25-64$ years) is $39.3 \%$, while that of general obesity is $21.6 \%$. These values are slightly higher in men (22.8\% compared to $20.5 \%$ in women), and the prevalence increases with age [5].

In recent years, it has been shown that the excess and distribution of body fat increases morbidity, with excess visceral fat being the most important factor that triggers pathologies $[6,7]$, especially in the cardiovascular system $[8,9]$.

Another major problem associated with visceral fat is metabolic syndrome, which is related to alterations in the lipid profile, inflammation and insulin resistance [10], partly due to a decrease in adiponectin, a molecule with antidiabetic, antiatherosclerotic and antiinflammatory functions [11].

Estimation of visceral fat makes it possible to identify patients with a higher cardiovascular risk, aiding the management of obesity [3]. Men present more abdominal fat than women, mainly in the form of visceral fat $[12,13]$.

New risk factors for cardiovascular diseaseVD have been identified, related to the excessive consumption of processed food products with high energy values and low nutritional values combined with a sedentary lifestyle [14]. Obesity and cardiovascular risk are closely linked, so in their prevention it is important to assess the patients' ability and willingness to change their lifestyle [15]. A combination of diet and physical activity seems insufficient to implement a successful program with sustained long-term results. According to the results obtained, $50 \%$ of the individuals who initially lose weight by dieting recover it in the following 12-30 months $[16,17]$. A recent review argues that lifestyle change interventions have proven to be the most effective tools in the treatment of obesity and overweight in adults. These should combine diet, exercise and cognitive-behavioral therapy $[18,19]$.

Based on the above, the main objective of the present study was to identify predictors of the visceral fat index after carrying out a multicomponent lifestyle change intervention. A secondary objective was to observe the effect of the intervention on dietary habits and functional capacity.

\section{Materials and Methods}

Design

A randomized intervention, parallel-group study was designed and carried out in Torrent, Spain. To obtain data in order to make an inter-and intragroup comparison of the results, two measurements were conducted, one before applying the program (baseline) and another after its completion (follow-up).

\section{Sampling and Recruitment}

The sample consisted of obese and overweight people. The inclusion criteria were: being between 20 and 70 years old, having a BMI higher than 25 , not doing regular physical exercise, having an adequate state of health to be able to carry out the physical activity program, and living in a "low" $(<14,755$ Euros) median household income census tract [20]. The exclusion criteria were having a diagnosis of heart, kidney or liver failure, respiratory problems that could limit the application of the program, a cardiovascular event during the last year and not agreeing to follow the proposed intervention program.

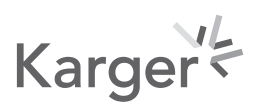


The software $G^{*}$ Power 3.1 was used to calculate the required sample size. To detect a 3 -kg difference between groups with a $5 \%$ alpha error $(\alpha=0.05)$ and a test power of $80 \%$, a sample size of 48 participants was needed, and 54 participants assuming a $10 \%$ attrition rate.

The recruitment took place between June and September 2014. An advertising strategy was designed in order to encourage recruitment. It consisted of mass media advertisements, posters and notices in leisure centers of the study location and advertising flyers in strategic places (market, fairs in the local festivities). Finally, a total of 97 participants were enrolled and allocated to the experimental group (EG) $(n=49)$, on which the lifestyle intervention program was implemented, and to the wait list control group $(n=48)$, who received no treatment that year.

Randomization to each group was carried out in a 4:4 allocation by means of a prespecified computer-generated randomization list by an investigator blinded to the study's objective. Likewise, to eliminate possible bias during the measurements, the patients were assessed by investigators who were blinded to the treatment allocation and the intervention program. Approval was obtained from the University of Valencia Research in Humans Ethics Committee, procedure No. H1427122754390, and all participants signed an informed consent form.

\section{Data Collection}

Visceral Fat Index

The Tanita BC 418 MA Segmental Body Composition Analyzer (Tanita Corp.; Tokyo, Japan) was used to measure the visceral fat index. This is a single-frequency bioelectrical impedance analysis device that uses 8 polar electrodes. The protocol proposed by Martínez [21], was followed to ensure the prediction accuracy of the bioimpedance equations.

Functional Capacity

On the test day, subjects first completed a 10-min warm-up led by an exercise instructor, before completing a balance test and 4 items of the senior fitness test validated by Rikli and Jones [22].

The Y test [23] was used to assess lower limb balance. During the test, all participants stood on the center of the grid with a single leg. We asked them to maintain this position and make their contralateral lower limb touch as far as possible along three lines: posteriolateral, posteriomedial and anterior. Participants completed three consecutive trials for each reach direction, and the maximum distance achieved in each trial was recorded. After completion of all three trials along the three lines, the longest reach distance in each direction was used for the analysis. The reach distance data were normalized with leg length to exclude the influence of this factor. Leg length was measured with a tape measure from the anterior superior iliac spine to the center of the medial malleolus. The composite score was calculated according to the formula [(sum of all three directions)/(limb length $\times 3)] \times 100$.

Then the participants performed the items of the senior fitness test. The "chair sit and reach test" was used to assess lower body flexibility. The score was the best distance achieved between the extended fingers and the tip of the toe. The "chair stand test" was used to measure lower body strength. The score was the total number of stands executed correctly within 30 s. The "arm curl test" was used to assess upper body strength. The score was the total number of hand weight curls through the full range of motion in $30 \mathrm{~s}$. The "6-min walk test" was used to measure aerobic endurance. The score was the total distance walked or run in 6 min along a $40 \times 20 \mathrm{~m}$ rectangular course, which was marked every $10 \mathrm{~m}$.

A familiarization session was performed 2 days beforehand, and participants received verbal instruction and a visual demonstration before performing practice trials to avoid any learning effect on the results.

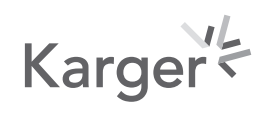


Table 1. Demographics of participants

\begin{tabular}{|c|c|c|c|c|}
\hline Demographics & $\begin{array}{l}\text { CG } \\
(n=27)\end{array}$ & $\begin{array}{l}\mathrm{EG} \\
(n=40)\end{array}$ & $\begin{array}{l}\text { Total } \\
(N=67)\end{array}$ & Significance \\
\hline Mean age (SD), years & $51.33(13.17)$ & $49.80(11)$ & $50.42(11.93)$ & $0.610^{\mathrm{a}}$ \\
\hline Gender (female), $n(\%)$ & $22(81.5)$ & $35(87.5)$ & $57(85.1)$ & $0.498^{\mathrm{a}}$ \\
\hline \multicolumn{5}{|c|}{ Highest education level, $n(\%)$} \\
\hline None & $4(14.8)$ & $3(7.5)$ & $7(10.4)$ & \multirow[t]{4}{*}{$0.706^{\mathrm{b}}$} \\
\hline Primary & $10(37)$ & $13(32.5)$ & $23(34.3)$ & \\
\hline Secondary & $6(22.2)$ & $10(25)$ & $16(23.9)$ & \\
\hline College & $7(25.9)$ & $14(35)$ & $21(31.3)$ & \\
\hline \multicolumn{5}{|l|}{ Work situation, $n(\%)$} \\
\hline Unemployed & $20(74.1)$ & $36(90)$ & $56(83.6)$ & \multirow[t]{4}{*}{$0.046^{\mathrm{b}}$} \\
\hline Employed & $0(0)$ & $2(5)$ & $2(3)$ & \\
\hline Retired & $4(14.8)$ & $2(5)$ & $6(9)$ & \\
\hline Permanent disability & $3(11.1)$ & $0(0)$ & $3(4.5)$ & \\
\hline
\end{tabular}

CG, control group; EG, experimental group; SD, standard deviation. ${ }^{a} t$ test. ${ }^{b} \chi^{2}$ test.

Food Consumption Frequency

Nutritional habits were evaluated using the validated Food Consumption Frequency questionnaire used recently in works carried out in the Spanish population [24]. It consists of a list of 93 foods, where the subjects must indicate the frequency of consumption of a standard unit or portion of each item using one of the 9 possible frequencies of consumption, ranging between "never or less than once a month" and "6 or more times a day" [25].

\section{Data Analysis}

The variables were reported as proportions and/or means and standard deviation. Parametric tests (Student's $t$ test) were used for the comparison of means, while nonparametric tests ( $\chi^{2}$ test) were used for the comparison of proportions. Postintervention variables were analyzed using a two-way mixed-effect (between-within) ANOVA including 2 groups (intervention group and control group) $\times 2$ times (pretest and posttest values) with repeated measures for the latter factor using 95\% confidence intervals (CIs). Effect size (partial $\eta^{2}$ ) for ANOVA was also calculated, with values of $>0.01$ being considered small, $>0.06$ considered moderate and $>0.15$ considered large [26].

The degree of association between the visceral fat index and the different factors was studied, and a linear regression model was constructed to assess the importance of the factors in relation to the visceral fat index after the intervention program.

We first considered the complete model with all the variables found in the bivariate analysis to be significantly associated with the visceral fat index. In a second step we eliminated from the model all the variables that failed to produce an important change (defined as the absence of an adjusted effect of $>10 \%$ ) or which did not result in an improved standard error of the estimate on adjusting the model without such variables. Consensus was sought among the investigators in cases where two or more subsets of variables with the same degree of fit were obtained.

Based on these criteria, the variables included in the model were: age, sex, work situation, group, arm strength, leg strength, flexibility, cardiorespiratory fitness, right-side balance, leftside balance, fruit, cereals, fatty and processed meats and dairy products. The dependent variable was the visceral fat index.

The study data were entered in MS Excel spreadsheets; then statistical analysis was performed using SPSS ${ }^{\circledR}$ version 23.0 (IBM SPSS Statistics).

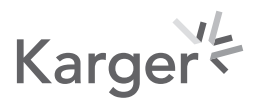


Table 2. Values obtained in the descriptive analysis and results of the time $\times$ group comparative analysis for the visceral fat index and physical condition variables

\begin{tabular}{|c|c|c|c|c|c|c|c|}
\hline \multirow[t]{2}{*}{ Variable } & \multirow[t]{2}{*}{ Group } & \multirow[t]{2}{*}{$\begin{array}{l}\text { Pretest } \\
\text { mean (SD) }\end{array}$} & \multirow[t]{2}{*}{$\begin{array}{l}\text { Posttest } \\
\text { mean (SD) }\end{array}$} & \multirow[t]{2}{*}{$\begin{array}{l}\text { Pretest vs. posttest } \\
\text { mean difference }(95 \% \mathrm{CI})\end{array}$} & \multicolumn{3}{|c|}{$\begin{array}{l}\text { Between-group } \\
\text { difference }\end{array}$} \\
\hline & & & & & $F$ & sig. & $\eta_{p}^{2}$ \\
\hline \multirow[t]{2}{*}{ Visceral fat index } & CG & $12.11(6.11)$ & $12(6.5)$ & $-0.11(-0.62$ to 0.85$)$ & \multirow[t]{2}{*}{4.47} & \multirow[t]{2}{*}{$0.038^{*}$} & \multirow[t]{2}{*}{0.067} \\
\hline & EG & $11.31(2.6)$ & $10.18(2.5)$ & $1.13(0.51$ to 1.74$)$ & & & \\
\hline \multirow[t]{2}{*}{ Strength arms, repetitions } & CG & $19.38(6.94)$ & $19.96(7.33)$ & $-0.57(-2.29$ to 1.13$)$ & \multirow[t]{2}{*}{45.65} & \multirow[t]{2}{*}{$<0.001^{*}$} & \multirow[t]{2}{*}{0.416} \\
\hline & $\mathrm{EG}$ & $20.83(4.82)$ & $28.85(5.47)$ & $-8.02(-9.40$ to -6.65$)$ & & & \\
\hline \multirow[t]{2}{*}{ Strength legs, repetitions } & CG & $18.61(6.51)$ & $17.46(5.84)$ & $1.15(-2.8$ to 0.49$)$ & \multirow[t]{2}{*}{55.89} & \multirow[t]{2}{*}{$<0.001^{*}$} & \multirow[t]{2}{*}{0.466} \\
\hline & EG & $17.72(4.33)$ & $24.50(5.46)$ & $-6.77(-8.10$ to -5.45$)$ & & & \\
\hline \multirow[t]{2}{*}{ Flexibility, cm } & CG & $-4.24(10.51)$ & $-5.48(9.78)$ & $1.23(-2.9$ to 0.43$)$ & \multirow[t]{2}{*}{34.66} & \multirow[t]{2}{*}{$<0.001^{*}$} & \multirow[t]{2}{*}{0.351} \\
\hline & $\mathrm{EG}$ & $-3.37(11.48)$ & $1.71(10.70)$ & $-5.08(-6.44$ to -3.72$)$ & & & \\
\hline \multirow[t]{2}{*}{ Aerobic endurance, min } & CG & $588.75(107.54)$ & $587.20(104.47)$ & $1.54(-31.08$ to 34.17$)$ & \multirow[t]{2}{*}{46.51} & \multirow[t]{2}{*}{$<0.001^{*}$} & \multirow[t]{2}{*}{0.437} \\
\hline & EG & $599.89(105.29)$ & $738.03(147.25)$ & $-138.13(-172.13$ to -104.14$)$ & & & \\
\hline \multirow[t]{2}{*}{ Balance right, $\mathrm{cm}$} & CG & $69.87(18.72)$ & $72.85(12.01)$ & $-2.97(-9.20$ to 3.25$)$ & \multirow[t]{2}{*}{2.95} & \multirow[t]{2}{*}{0.091} & \multirow[t]{2}{*}{0.045} \\
\hline & EG & $75.64(16.01)$ & $85.47(14.16)$ & $-9.83(-14.86$ to -4.81$)$ & & & \\
\hline \multirow[t]{2}{*}{ Balance left, cm } & CG & 69.77 (16.67) & $71.66(13.24)$ & $-1.89(-7.88$ to 4.09$)$ & \multirow[t]{2}{*}{4.77} & \multirow[t]{2}{*}{$0.033^{*}$} & \multirow[t]{2}{*}{0.071} \\
\hline & EG & $77.24(15.32)$ & $87.52(15.14)$ & $-10.28(-15.04$ to -5.51$)$ & & & \\
\hline
\end{tabular}

SD, standard deviation; CI, confidence interval; CG, control group; EG, experimental group. $F$ by ANOVA test. sig., significance; $* p<0.05 . \eta_{\mathrm{p}}{ }^{2}$, effect size. Thresholds for $\eta^{2}:>0.01$, small; $>0.06$, moderate; $>0.15$, large.

\section{Results}

\section{Sample Characteristics}

Of the 97 subjects who completed the preintervention test, 67 completed the postintervention test (EG, $n=40$; controls, $n=27$ ). The demographics of the participants are shown in Table 1.

\section{Visceral Fat Index and Physical Condition}

Results for visceral fat index and physical condition (Table 2) show the effect of interaction between these variables in both groups, except for right-leg balance.

Changes in visceral fat index are shown in Figure 1a. They reveal statistically significant $(p<0.01)$ changes over time for the EG.

Physical condition results are shown in Figure 1b-g. Statistically significant differences $(p<0.001)$ can be observed between the two measurements in the EG for all the variables. Changes between groups can also be observed in the postintervention measurement for all the physical condition variables.

\section{Frequency of Food Consumption}

Table 3 shows the percentage of subjects who are within the recommendations for each food group before and after the intervention.

\section{Visceral Fat Prediction Model}

Due to the existence of factors that can predict visceral fat values to a greater or lesser extent, a predictive model of the visceral fat index was developed based on the criteria described in the Methods section. 


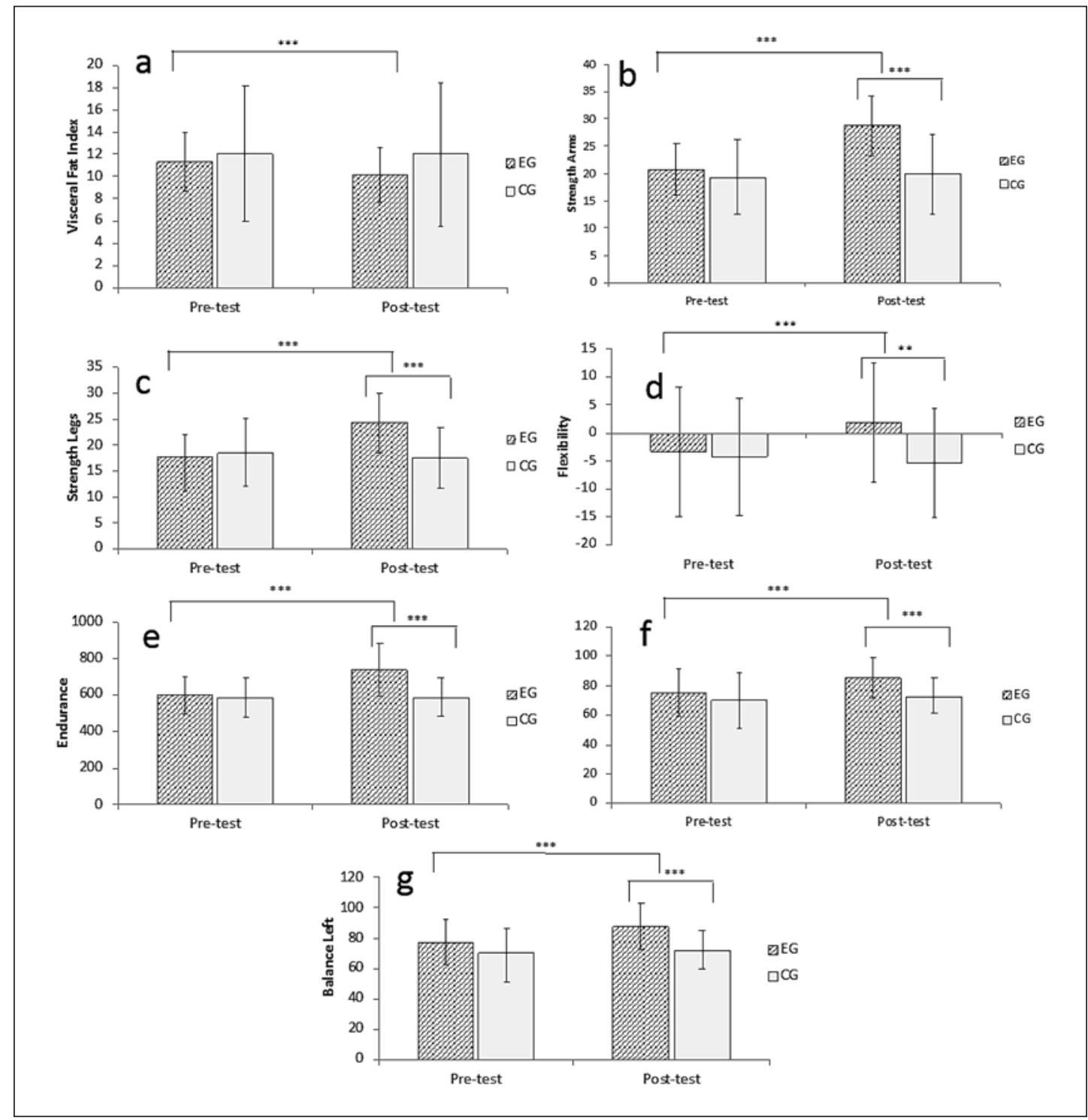

Fig. 1. Simple effects of mixed analysis of variance for: visceral fat index (a); strength in arms (b); strength in legs (c); flexibility (d); endurance (e); balance over the right leg (f); balance over the left leg (g). EG, experimental group; CG, control group.

Female sex ( $\beta=-5.31 ; 95 \% \mathrm{CI}:-7.88$ to $-2.75 ; p<0.001)$, intake of recommended daily portions of fruit ( $\beta=-1.49 ; 95 \% \mathrm{CI}:-3.29$ to $0.3 ; p=0.1$ ), gain in lower limb strength $(\beta=$ -0.06 ; $95 \% \mathrm{CI}:-0.23$ to $0.11 ; p=0.497$ ) and gain in flexibility ( $\beta=-0.14 ; 95 \% \mathrm{CI}:-0.33$ to $0.05 ; p=0.148)$ are prescriptive factors of lower visceral fat index. Age over 45 years $(\beta=$ 3.31; $95 \% \mathrm{CI}: 1.21-5.41 ; \mathrm{p}=0.003)$ and intake of the recommended weekly portion of cereals $(\beta=6.25 ; 95 \% \mathrm{CI}:-0.77$ to $13.27 ; p=0.08)$ and fatty and processed meats $(\beta=1.98 ; 95 \% \mathrm{CI}$ : $0.11-3.85 ; p=0.038)$ increase the visceral fat index after carrying out a multicomponent lifestyle change program. This model yielded $R^{2}=0.42(F=5.52, p<0.001)$ (Fig. 2). The regression equation was:

visceral fat index $=12.67-(5.31 \times$ female sex $)-(1.49 \times$ fruit $)-(0.06 \times$ gain in left-limb strength $)-(0.14 \times$ gain in flexibility $)+(3.31 \times$ age $>45$ years $)+(6.925 \times$ cereals $)+(1.98 \times$ fatty and processed meats). 


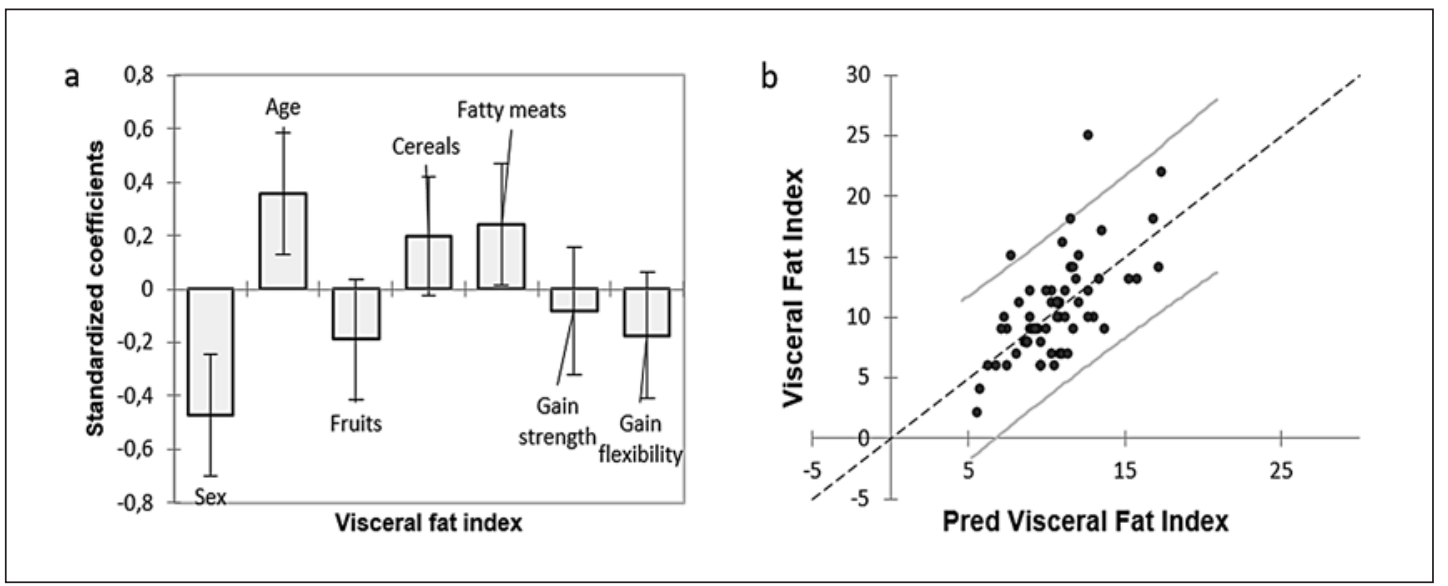

Fig. 2. a Standardized coefficients of predictors of visceral fat index ( $95 \%$ confidence interval). b Prediction model of visceral fat index (95\% confidence interval).

Table 3. Percentage of subjects who are within the nutritional recommendations depending on the group (control vs. experimental)

\begin{tabular}{|c|c|c|c|c|c|}
\hline \multirow[t]{2}{*}{ Food } & \multirow[t]{2}{*}{ Recommendations } & \multicolumn{2}{|c|}{ Pretest percentage } & \multicolumn{2}{|c|}{ Posttest percentage } \\
\hline & & CG & EG & CG & EG \\
\hline Fish and seafood & 3-4 servings a week & 12.5 & 7.7 & 20.8 & 15.4 \\
\hline Lean meat and poultry & 3-4 servings a week & 12.5 & 41.0 & 4.2 & 15.4 \\
\hline Eggs & 3-4 servings a week & 0.0 & 0.0 & 0.0 & 0.0 \\
\hline Legumes & $2-4$ servings a week & 16.7 & 30.8 & 8.3 & 12.8 \\
\hline Dairy & 2-4 servings a day & 50.0 & 51.3 & 33.3 & 43.6 \\
\hline Nuts and seeds & 3-7 servings a week & 8.3 & 10.3 & 8.3 & 7.7 \\
\hline Olive oil & $3-6$ servings a day & 4.2 & 20.5 & 12.5 & 7.7 \\
\hline Vegetables & More than 2 servings a day & 83.3 & 92.3 & 83.3 & 94.9 \\
\hline Fruits & More than 3 servings a day & 41.7 & 48.7 & 37.5 & 51.3 \\
\hline Cereals & 4-6 servings a day & 0.0 & 5.1 & 0.0 & 2.6 \\
\hline Water & $4-8$ servings a day & 4.2 & 2.6 & 8.3 & 7.7 \\
\hline Sweets & Use sparingly & 45.8 & 28.2 & 50.0 & 41.0 \\
\hline Soft drinks & Use sparingly & 95.8 & 84.6 & 95.8 & 94.9 \\
\hline Fats & Use sparingly & 83.3 & 79.5 & 87.5 & 87.2 \\
\hline High-fat and processed meats & Use sparingly & 50.0 & 17.9 & 58.3 & 61.5 \\
\hline
\end{tabular}

Pretest, percentage of subjects who are within the nutritional recommendations at baseline; posttest, percentage of subjects who are within the nutritional recommendations after the intervention; CG, control group; EG, experimental group.

\section{Discussion/Conclusion}

The current trend in the management of obesity consists of multicomponent programs that integrate diet, exercise and cognitive behavioral therapy $[18,19]$.

The objective of this study was to observe changes in the visceral fat index after the intervention and their relationship with eating habits and functional capacity, which, as the literature demonstrates, are associated with an increased risk of morbidity [3, 6, 27]. Being female, fruit consumption, gain in leg strength and flexibility have been shown to be predictors of visceral fat reduction. In contrast, age over 45 years, consumption of fatty and processed meats and consumption of cereals proved to be potentiating predictors. 
López-Hernández et al.: Predictors of Visceral Fat in the Obese Population

Regarding the effect of the intervention, significant improvements were observed after the intervention in the EG for all the functional capacity variables. Improvements in strength and aerobic capacity are related to cardiovascular benefits. The decrease in visceral fat produces metabolic and respiratory improvements [28]. Improved balance is associated with a lower risk of falls $[29,30]$ due to obese participants having reduced postural balance compared with their nonobese peers. All this, linked with improvements in flexibility, directly affects the ability to perform activities of daily living [31].

With regard to eating habits, unlike other studies with similar samples [32, 33], the favorable changes expected in the consumption of the recommended portions were not achieved in our study. Favorable changes were only achieved for food groups whose recommended consumption is occasional, such as soft drinks, fats and fatty and processed meats. In this case, there was an increase in the percentage of EG participants with a normalized consumption after the intervention.

Low socioeconomic status could influence food selection, not only as a consequence of not being able to acquire certain foods because of their economic cost, but also because of the degree of knowledge related to food and, in some cases, because of sensory preferences [34]. In addition, there are studies showing that today's food environment in developed countries promotes food preferences and food selection that are not in line with healthy dietary guidelines, thus promoting excessive weight gain and obesity [35]. Furthermore, authors such as Manyanga et al. [36] establish that unhealthy dietary patterns are directly related to low socioeconomic status. It is likely that if they had had a sample of people with a higher socioeconomic status, they would have been able to acquire any food regardless of the economic cost. The possibility of choice according to preference facilitates the monitoring of an eating plan. With higher cultural knowledge they would probably have less difficulty in interpreting food labeling, especially at the beginning of the study [34]. These aspects could have resulted in greater weight loss in the first few weeks, which would have helped maintain their level of motivation and reduced the rate of abandonment of the program. In addition, food selection in higher-income households is related to the choice of ultraprocessed foods, because of their poor culinary preparation where less preparation time is spent and they are ready to eat and also have a longer shelf life [35, 37].

A previous study [38] showed that with a successful medical management, patients reported a greater intention to lose weight, although no differences were found for intentions to change their diet or to become more active. After analyzing our data, we can conclude that changes in diet are more complicated to achieve than changes in physical activity.

Regarding the predictive factors of visceral fat index, female sex was associated with a lower index. This aspect could be related to fat distribution according to sex. The male sex typically presents greater central and upper body fat accumulation while the female sex shows more peripheral and lower body fat. Genetic determinants and hormonal factors probably also contribute to this distribution [39].

Age is a predictor of a higher visceral fat index. As age increases, there is a decrease in basal energy expenditure, which in turn is related to a decrease in lean tissue and the consequent reduction of metabolic activity [40].

Despite the increase in recommended portions of cereals, their consumption is related to a higher fat index. This aspect could be related to a high consumption of refined cereals [41]. A lower consumption of refined grains in favor of the consumption of more whole grain cereals is associated with protection against chronic degenerative diseases, such as diabetes or metabolic syndrome, and the maintenance of body weight [42]. In addition, several epidemiological studies show that the Western diet, which includes high amounts of red meat, dairy products and refined cereals, is associated with cardiovascular disease [43], one of the main risk factors for a high visceral fat index [44].

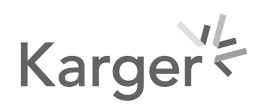


An association between the gain in flexibility and a greater decrease in visceral fat is also observed. This result may be related to the limited range of motion suffered by the obese population. Body fat acts as a biomechanical barrier and hinders joint mobility [45], which can have an impact on increased injuries and pain and loss of balance [31].

Finally, there was also a positive association between leg strength and a greater decrease in visceral fat, which is consistent with the findings of studies such as that of Albright et al. [46], in which it was observed that progressive resistance exercise training has positive effects on insulin sensitivity and other processes associated with visceral adipose tissue accumulation. Furthermore, there is evidence that by incurring a significantly lower energy expenditure than aerobic exercise, progressive resistance exercise may directly reduce visceral adipose tissue [47].

The present study is not exempt from limitations. Firstly, there may be bias in obtaining the information in the Food Consumption Frequency questionnaire, since it is completed by the subject. However, it is difficult to know reliably whether the data given are truthful. There may have been contamination between groups if they belong to the same population and are familiar with the program. Similarly, the control group could have been influenced by the Hawthorne effect. Finally, in this type of intervention it is necessary to know the long-term effect rather than just completing the program, since this would make it possible to observe the long-term effects of the intervention.

Following a multicomponent intervention in obese people with low socioeconomic status, the visceral fat index decreases. Female sex, daily recommended intake of fruit rations, gain in leg strength and gain in flexibility are predictive factors of a lower visceral fat index. Despite the increase in the recommended portions of cereals, their consumption is related to a higher fat index. Moreover, age over 45 years and higher consumption of meats, fat and processed meats per week increases the rate of visceral fat. Compliance of the program improves functional capacity, although scarce modifications in eating habits were observed.

Despite following a multicomponent program with physical exercise, psychological counseling and nutritional education, no change in eating habits has been achieved. The main difficulty could be low socioeconomic level. In view of the results obtained, it could be concluded that people over 45 years old who do not have an adequate diet that is even a little high in meats, fat and cereals have a greater risk of visceral fat and therefore cardiovascular risk.

Some studies argue that although high-income countries have a high cardiovascular risk, low-income countries have a higher number of cardiovascular events [48, 49], which could be associated with other factors related to low socioeconomic status, such as accessibility to health care and pharmacological care.

Health education as part of health promotion and prevention strategies is responsible for encouraging the acquisition of knowledge and motivation to be able to opt for healthy lifestyles, in addition to having the necessary conditions. These strategies are even more important in the most vulnerable groups, where food price policies should also be included in order to promote healthier and more varied diets $[49,50]$. When resources are limited, it is precisely the sectors of society most in need that are most affected [49].

\section{Acknowledgment}

The authors would like to thank all of the participants in this research, without whom the study would not have been possible, and the Universidad Católica de Valencia "San Vicente Mártir" for its support.

\section{Karger'}


López-Hernández et al.: Predictors of Visceral Fat in the Obese Population

\section{Statement of Ethics}

All study procedures involving human participants were carried out in accordance with the ethical standards of the institutional regulations of the Spanish legislation on clinical trials (Royal Decree 223/2004, of February 6) and the 1964 Declaration of Helsinki and its later amendments or comparable ethical standards. Approval was obtained from the University of Valencia Research in Humans Ethics Committee, procedure No. H1427122754390, and all participants signed an informed consent form.

The authors confirm that all personal identifiers have been removed or disguised so that the persons described are not identifiable and cannot be identified through details of their story.

\section{Disclosure Statement}

The authors declare that there are no conflicts of interest.

\section{Funding Sources}

The charge for article processing (APC) is funded by the Universidad Católica de Valencia San Vicente Mártir.

\section{Author Contributions}

Ana Pablos and Laura Elvira designed the study. Pilar Pérez-Ros and Ana Pablos were responsible for the statistical design and analysis. Lourdes Lopez-Hernandez, Pilar PérezRos, María Fargueta, Josep López-Soler and Ana Pablos wrote the article. Lourdes LopezHernandez, María Fargueta, Laura Elvira and Ana Pablos collected data. All authors approve the final version of the paper.

\section{References}

1 OMS. Obesidad y sobrepeso. [cited 2018 Feb 26). Available from: http://www.who.int/mediacentre/factsheets/fs311/es/

2 Frühbeck G, Toplak H, Woodward E, Yumuk V, Maislos M, Oppert JM. Obesity: the gateway to ill health - an EASO position statement on a rising public health, clinical and scientific challenge in Europe. Obes Facts. 2013 Apr;2(6):117-120.

3 Gómez-Ambros J, González-Crespo I, Catalán V, Rodríguez A, Moncada R, Valentí V, et al. Clinical usefulness of abdominal bioimpedance (ViScan) in the determination of visceral fat and its application in the diagnosis and management of obesity and its comorbidities. Clin Nutr. 2017 Apr;2(37):580-589.

4 Martínez-Corona M, Barceló M, Gómez-González R, Ramírez D. Circunferencia de la cintura, tamaño de la grasa visceral y trastornos metabólicos en la obesidad mórbida. Rev Cubana Aliment Nutr. 2015 Jan;1(25):20-47.

5 Aranceta J, Pérez C, Alberdi G, Ramos N, Lázaro S. Prevalencia de obesidad general y obesidad abdominal en la población adulta española (25-64 años) 2014-2015: estudio ENPE. Rev Esp Cardiol. 2016 Jun;69(6):579-87.

6 Ismail I, Keating SE, Baker MK, Johnson NA. A systematic review and meta-analysis of the effect of aerobic vs. resistance exercise training on visceral fat. Obes Rev. 2012 Jan;13(1):68-91.

7 Xiao T, Fu YF. Resistance training vs. aerobic training and role of other factors on the exercise effects on visceral fat. Eur Rev Med Pharmacol Sci. 2015 May;19(10):1779-84.

8 Rosales Y. Antropometría en el diagnóstico de pacientes obesos: una revisión. Nutr Hosp. 2012 Nov; 6(27): 1803-9.

9 Shields M, Tremblay MS, Connor Gorber S, Janssen I. Abdominal obesity and cardiovascular disease risk factors within body mass index categories. Health Rep. 2012 Jun;23(2):7-15.

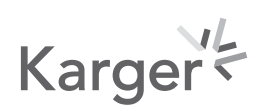




\begin{tabular}{l|l}
\hline \multicolumn{2}{l}{ Obes Facts 2020;13:403-414 } \\
\hline DOI: 10.1159/000507960 & $\begin{array}{l}\text { @ 2020 The Author(s). Published by S. Karger AG, Basel } \\
\text { www.karger.com/ofa }\end{array}$ \\
\hline
\end{tabular}

López-Hernández et al.: Predictors of Visceral Fat in the Obese Population

10 Després JP, Lemieux I. Abdominal obesity and metabolic syndrome. Nature. 2006 Dec;444(7121):881-7.

11 Matsuzawa Y, Funahashi T, Kihara S, Shimomura I. Adiponectin and metabolic syndrome. Arterioscler Thromb Vasc Biol. 2004 Jan;24(1):29-33.

12 Garaulet M, Puy M, Pérez F, Cuadrado C, Leis R, Moreno MJ. Obesidad y ciclos de vida del adulto. Rev Esp Nutr Comunitaria. 2008 Feb;3(14):150-5.

13 Maury E, Brichard SM. Adipokine dysregulation, adipose tissue inflammation and metabolic syndrome. Mol Cell Endocrinol. 2010 Jan;314(1):1-16.

14 Després JP. Body fat distribution and risk of cardiovascular disease: an update. Circulation. 2012 Sep;126(10): 1301-13.

15 Cuadri JC, Tornero IT, Sierra AS, Sáez JM. Revisión sistemática sobre los estudios de intervención de actividad física para el tratamiento de la obesidad (Systematic review of physical activity programs for the treatment of obesity). Retos. 2018 Jul;33:261-6.

16 Jakicic JM, Rickman AD, Lang W, Davis KK, Gibbs BB, Neiberg R, et al. Time-based physical activity interventions for weight loss: a randomized trial. Med Sci Sports Exerc. 2015 May;47(5):1061-9.

17 Sullivan DK, Goetz JR, Gibson CA, Mayo MS, Washburn RA, Lee Y, et al. A virtual reality intervention (Second Life) to improve weight maintenance: rationale and design for an 18-month randomized trial. Contemp Clin Trials. 2016 Jan;46(46):77-84.

18 Gómez Puente JM, Martínez-Marcos M. Sobrepeso y obesidad: eficacia de las intervenciones en adultos. Enferm Clin. 2018 Jan-Feb;28(1):65-74.

19 Lin H, Zhang L, Zheng R, Zheng Y. The prevalence, metabolic risk and effects of lifestyle intervention for metabolically healthy obesity: a systematic review and meta-analysis: A PRISMA-compliant article. Medicine (Baltimore). 2017 Nov;96(47):e8838.

20 Ard JD, Gower B, Hunter G, Ritchie CS, Roth DL, Goss A, et al. Effects of calorie restriction in obese older adults: the CROSSROADS randomized controlled trial. J Gerontol A Biol Sci Med Sci. 2017 Dec;73(1): 73-80.

21 Martínez EG. Composición corporal: su importancia en la práctica clínica y algunas técnicas relativamente sencillas para su evaluación. Salud Uninorte. 2010 Feb;1(26):98-116.

22 Rikli RE, Jones JC. Development and validation of a functional fitness test for community-residing older adults. J Aging Phys Act. 1999 Ap;(7):129-61.

23 Plisky PJ, Gorman PP, Butler RJ, Kiesel KB, Underwood FB, Elkins B. The reliability of an instrumented device for measuring components of the star excursion balance test. N Am J Sports Phys Ther. 2009 May;4(2):92-9.

24 Ciprián D, Navarrete-Muñoz EM, Garcia de la Hera M, Giménez-Monzo D, González-Palacios S, Quiles J, et al. [Mediterranean and Western dietary patterns in adult population of a Mediterranean area: a cluster analysis]. Nutr Hosp. 2013 Sep-Oct;28(5):1741-9. Spanish.

25 Feskanich D, Rimm EB, Giovannucci EL, Colditz GA, Stampfer MJ, Litin LB, et al. Reproducibility and validity of food intake measurements from a semiquantitative food frequency questionnaire. J Am Diet Assoc. 1993 Jul; 93(7):790-6.

26 Cohen J. Statistical power analysis for the behavioral sciences. Abingdon: Routledge; 1988.

27 González Calvo G, Hernández Sánchez S, Pozo Rosado P, García López D. Asociación entre tejido graso abdominal y riesgo de morbilidad: efectos positivos del ejercicio físico en la reducción de esta tendencia. Nutr Hosp. 2011 Jul-Aug;26(4):685-91.

28 Miller CT, Fraser SF, Straznicky NE, Dixon JB, Selig SE, Levinger I. Effect of diet versus diet and exercise on weight loss and body composition in class II and III obesity: a systematic review. J Diabetes Metab. 2013 Jan; 6(4):1-6.

29 Mitchell RJ, Lord SR, Harvey LA, Close JC. Associations between obesity and overweight and fall risk, health status and quality of life in older people. Aust N Z J Public Health. 2014 Feb;38(1):13-8.

30 Neri SG, Gadelha AB, de David AC, Ferreira AP, Safons MP, Tiedemann A, et al. The Association Between Body Adiposity Measures, Postural Balance, Fear of Falling, and Fall Risk in Older Community-Dwelling Women. J Geriatr Phys Ther. 2019 Jul/Sep;42(3):E94-100.

31 Gadelha AB, Neri SG, Safons MP, Moreira SR, Lima RM. Comparisons between body adiposity indexes and cutoff values in the prediction of functional disability in older women. Rev Bras Cineantropom Desempenho Hum. 2016 Jul;18(4):381-90.

32 Arrebola E, Gómez-Candela C, Fernández C, Bermejo L, Loria V. Eficacia de un programa para el tratamiento del sobrepeso y la obesidad no mórbida en atención primaria y su influencia en la modificación de estilos de vida. Nutr Hosp. 2013 Jan;28:137-41.

33 Donini LM, Cuzzolaro M, Gnessi L, Lubrano C, Migliaccio S, Aversa A, et al. Obesity treatment: results after 4 years of a Nutritional and Psycho-Physical Rehabilitation Program in an outpatient setting. Eat Weight Disord. 2014 Jun;19(2):249-60.

34 Araya M, Atalah E. Factores que determinan la selección de alimentos en familias de sectores populares. Rev Chil Nutr. 2002 Mar;29(3):308-15.

35 St-Onge MP, Keller KL, Heymsfield SB. Changes in childhood food consumption patterns: a cause for concern in light of increasing body weights. Am J Clin Nutr. 2003 Dec;78(6):1068-73.

36 Manyanga T, Tremblay MS, Chaput JP, Katzmarzyk PT, Fogelholm M, Hu G, et al.; ISCOLE Research Group. Socioeconomic status and dietary patterns in children from around the world: different associations by levels of country human development? BMC Public Health. 2017 May;17(1):457. 
37 Vedovato GM, Trude AC, Kharmats AY, Martins PA. Degree of food processing of household acquisition patterns in a Brazilian urban area is related to food buying preferences and perceived food environment. Appetite. 2015 Apr;87:296-302.

38 Ogden J, Arulgnanaseelan J. Medically managing obesity: offering hope or a disincentive to change? Patient Educ Couns. 2017 Jan;100(1):93-7.

39 Godínez SA, Marmol GE, Márquez E, Vázquez JJ, Baeza R. La grasa visceral y su importancia en obesidad. Rev Endocrinol Nutr. 2002 May;3(10):121-7.

40 Pavón I, Alameda C, Olivar J. Obesidad y menopausia. Nutr Hosp. 2006 Jul;6(21):633-7.

41 McKeown NM, Troy LM, Jacques PF, Hoffmann U, O’Donnell CJ, Fox CS. Whole- and refined-grain intakes are differentially associated with abdominal visceral and subcutaneous adiposity in healthy adults: the Framingham Heart Study. Am J Clin Nutr. 2010 Nov;92(5):1165-71.

42 Ortega RM, Aparicio A, Jiménez Ortega AI, Rodríguez-Rodríguez E. Cereales de grano completo y sus beneficios sanitarios. Nutr Hosp. 2015 Jul;32 Suppl 1:25-31.

43 Bonaccio M, Iacoviello L, de Gaetano G; Moli-Sani Investigators. The Mediterranean diet: the reasons for a success. Thromb Res. 2012 Mar;129(3):401-4.

44 Nicolalde TM, Guevara MS, Betancourt SL. Obesidad visceral, razón masa grasa/masa muscular y dislipidemia aterogénica: estudio transversal realizado en Riobamba, Ecuador. Rev Esp Nutr Hum Diet. 2015 Aug;19(3): 140-5.

45 Miller CT, Fraser SF, Levinger I, Straznicky NE, Dixon JB, Reynolds J, et al. The effects of exercise training in addition to energy restriction on functional capacities and body composition in obese adults during weight loss: a systematic review. PLoS One. 2013 Nov;8(11):e81692.

46 Albright A, Franz M, Hornsby G, Kriska A, Marrero D, Ullrich I, et al. American College of Sports Medicine position stand. Exercise and type 2 diabetes. Med Sci Sports Exerc. 2000 Jul;32(7):1345-60.

47 Kay SJ, Fiatarone Singh MA. The influence of physical activity on abdominal fat: a systematic review of the literature. Obes Rev. 2006 May;7(2):183-200.

48 Yan R, Li W, Yin L, Wang Y, Bo J, Liu L, et al.; PURE-China Investigators. Cardiovascular Diseases and RiskFactor Burden in Urban and Rural Communities in High-, Middle-, and Low-Income Regions of China: A Large Community-Based Epidemiological Study. J Am Heart Assoc. 2017 Feb;6(2):e004445.

49 Appiah D, Capistrant BD. Cardiovascular Disease Risk Assessment in the United States and Low- and MiddleIncome Countries Using Predicted Heart/Vascular Age. Sci Rep. 2017 Nov;7(1):16673.

50 Conklin AI, Monsivais P, Khaw KT, Wareham NJ, Forouhi NG. Dietary diversity, diet cost, and incidence of type 2 diabetes in the United Kingdom: a prospective cohort study. PLoS Med. 2016 Jul;13(7):e1002085. 